\title{
Predictors of institutionalisation in people with dementia
}

\author{
S Baneriee, J Murray, B Foley, L Atkins, J Schneider, A Mann
}

J Neurol Neurosurg Psychiatry 2003;74:1315-1316

Objective: To identify what patient and carer characteristics influence transition into residential care for people with dementia.

Method: Longitudinal study of a cohort of people with dementia and their carers in contact with old age psychiatric services in south London.

Results: 100 people with dementia and their main family carer were recruited. At six month follow up 22 were in residential care, 63 in the community, 8 had died, and for 7 there were missing data. Between six and 12 months, 7 of the 63 in the community went into residential care, 4 died, and 12 were lost to follow up. The most striking finding is the 20-fold protective effect of having a co-resident carer lodds ratio $0.05,95 \%$ confidence intervals 0.01 to $0.42, p=0.006)$. Higher ratings of behavioural problems in the person with dementia were also statistically significantly associated with transition into residential care as was the psychological domain of quality of life of the carer.

Conclusion: These findings powerfully illustrate the pivotal role carried out by carers of people with dementia; interventions directly targeted at helping them to maintain this role would be supported by these data. These data also suggest that strategies directed at improving carer quality of life and at the resolution of behavioural disorder in the person with dementia may also have particular value.

$\mathrm{T}$ he dementias are some of the most common and serious disorders in later life. They cause irreversible decline in global intellectual and physical functioning. There are profound impacts on the person with dementia, their family and carers, and also on health, social and voluntary services, in personal, social, health, and economic terms. ${ }^{1}$ The challenge of meeting the health and social care needs of people with dementia and their family carers is profound. ${ }^{2}$ A major element of the economic impact of caring for people with dementia is consequent to their increased risk of requiring admission into residential care. ${ }^{3}$ Taken with carer and patient choice, these costs have resulted in a focusing of policy on maintaining people with dementia in the community.

Patient characteristics such as increasing age, lower cognitive function, poorer self related health, increased limitation in activities of daily living, and not being married have all been reported to be associated with institutionalisation. ${ }^{4}$ A recent analysis of the people with Alzheimer's disease receiving Medicare has demonstrated the importance of considering both patient and caregiver characteristics simultaneously when considering nursing home placement in dementia. ${ }^{5}$ To formulate effective packages of support for carers and people with dementia it is necessary to identify what influences transition into residential care. We therefore carried out a study with that aim and we report data from this here.

\section{METHODS}

People diagnosed as having dementia by old age psychiatric services in south east London and living in the community were recruited along with their main family carer. They were assessed at baseline with a package of instruments including a record of sociodemographic data and measurement of: carer burden, ${ }^{6}$ carer mental disorder, ${ }^{7}$ carer quality of life, ${ }^{8}$ cognitive impairment in the person with dementia, ${ }^{9}$ and behaviour disturbance in dementia. ${ }^{10}$

Subjects were followed up for one year and were assessed at six and 12 months to ascertain place of residence.

To investigate predictors of transition to residential care, logistic regression analyses were completed to control for the effects of potential confounders on exposures of interest. Those for whom there were missing outcome data and those who died before follow up were excluded.

\section{RESULTS}

A total of $100(56 \%)$ of the 179 people with dementia and their main family carers approached were recruited. At six month follow up 22 were in residential care, 63 in the community, eight had died, and for seven there were missing data. Between six and 12 months, 7 of the 63 in the community went into residential care, four died, and 12 were lost to follow up.

Table 1 Logistic regression analyses of associations of characteristics measured at baseline and transition into residential care during the study period

\begin{tabular}{llll}
\hline & Odds ratio & 95\% Confidence limits & $\mathrm{p}$ Value \\
\hline Age-person with dementia & 1.01 & 0.96 to 1.28 & 0.155 \\
Female sex-person with dementia & 0.39 & 0.06 to 2.42 & 0.313 \\
Female sex-carer & 0.96 & 0.13 to 6.97 & 0.966 \\
Carer mental health & 0.71 & 0.13 to 3.99 & 0.697 \\
Carer quality of life-psychological & 1.10 & 1.02 to 1.19 & 0.018 \\
Person with dementia behaviour problems & 1.08 & 1.01 to 1.15 & 0.026 \\
Carer burden score & 1.02 & 0.96 to 1.08 & 0.542 \\
Person with dementia ADAS-Cog score & 1.02 & 0.96 to 1.07 & 0.532 \\
Spouse carer & 2.29 & 0.27 to 19.6 & 0.449 \\
Co-resident carer & 0.05 & 0.01 to 0.42 & 0.006 \\
\hline
\end{tabular}


The results of the logistic regression analyses carried out on the data obtained are summarised in table 1 . The most striking finding is the 20 -fold protective effect of having a co-resident carer, defined as the family carer living in the same household as the person with dementia (odds ratio $0.05,95 \%$ confidence intervals 0.01 to $0.42, \mathrm{p}=0.006$ ). Higher ratings of behavioural problems in the person with dementia were also statistically significantly associated with transition into residential care as was the psychological domain of quality of life of the carer.

\section{DISCUSSION}

These findings powerfully illustrate the pivotal role carried out by carers of people with dementia; having a co-resident carer made admission to a care home 20 times less likely over a one year period. The vast majority of the care provided for people with dementia is provided free by family carers and this study makes clear the potential value of supporting them.

There are potential limitations to this study, including: an element of response bias given that only $56 \%$ of the possible sample participated; the subjects coming from an urban area; and being secondary care contacts. These all may limit generalisability of the data presented here particularly to rural areas and to people with dementia not referred to old age psychiatric services. However, the methodology, which included simultaneous detailed assessment of the carer as well as the person with dementia, does have some strengths. In particular it allows our analyses to control for the effects of important potential confounders (for example, disease severity, behavioural disturbance, carer burden, and carer mental health) to investigate the predictive association of variables of interest with institutionalisation for people with dementia.

These data have practical implications in illustrating the potential value of co-resident carers in dementia and in helping to formulate strategies for the prevention of transition into residential care. Clearly co-resident carers play a vital part; interventions directly targeted at helping them to maintain this role would be supported by these data. Such support might be provided at multiple levels. On a national basis carers could be supported by specific financial benefits and improving public attitudes to and understanding of dementia. Locally, services such as carer support groups and the development of dementia services with a carer focus as outlined in the UK's National Service Framework for Older People $^{2}$ are likely to be of value. On an individual patient basis, early identification with deployment of psychosocial and possibly pharmacological interventions aimed at managing behavioural disorder in dementia alongside specific packages of practical psychosocial carer support directed at the carer for the carer would seem to be of potential worth. These strategies would be directed at preventing breakdown in home based care, improving carer quality of life, and at the resolution of behavioural disorder in the person with dementia. It has been argued powerfully that comparatively small changes in the balance between people with dementia being cared for at home rather than in institutional settings could unlock substantial funds to improve the quality of community based dementia care. ${ }^{1}$ The data presented from this study suggest areas of focus and content for interventions for people with dementia and their carers.

\section{ACKNOWLEDGEMENTS}

We would like to thank all the people with dementia and the carers who took part in the study. Thanks are also due to the clinicians who generated the cases for the study. This study was funded by the Department of Health's Policy Research Programme as part of its Community Health Services Research Initiative; the views reported are those of the authors.

\section{Authors' affiliations}

S Baneriee, J Murray, B Foley, L Atkins, A Mann, Section of Mental Health and Ageing, Health Services Research Department, The Institute of Psychiatry, London, UK

J Schneider, Centre for Applied Social Studies, Durham, UK

Competing interests: none declared.

Correspondence to: Professor S Banerjee, PO Box 26, Section of Mental Health and Ageing, Health Services Research Department, The Institute of Psychiatry, De Crespigny Park, London SE5 8AF, UK;

spjussb@iop.kcl.ac.uk

Accepted for publication 28 February 2003

\section{REFERENCES}

1 Bosanquet N. The socio-economic impact of dementia. International Journal of Geriatric Psychiatry 2001;16:249-53.

2 Department of Health. National Service framework for older people. London: Department of Health, 2001.

3 Eaker ED, Vierkant RA, Mickel SF. Predictors of nursing home admission and/or death in incident Alzheimer's disease and other dementia cases compared to controls: a population-based study. J Clin Epidemiol 2002;55:462-8.

4 St John PD, Montgomery PR, Kristiansson B, et al. Cognitive scores, even within the normal range predict death and institutionalisation. Age Ageing 2002;31:373-8

5 Yaffe K, Fox P, Newcomer R, et al. Patient and caregiver characteristics and nursing home placement in patients with dementia. JAMA 2002:287:2090-7.

6 Zarit SH, Reever KE, Bach-Peterson J. Relatives of the impaired elderly: correlates of feeling of burden. Gerontologist 1980;20:649-55.

7 Goldberg DP, Williams P. A user's guide to the General Health Questionnaire. Windsor: NFER-Nelson, 1988.

8 WHOQOL Group. WHOQOL-BREF. Introduction, administration, scoring and generic version of the assessment. Geneva: WHO, 1996.

9 Rosen WG, Mohs RC, Davis KL. A new rating scale for Alzheimer's disease. Am J Psychiatry 1984;141:1356-64.

10 Reisberg B, Borenstein J, Salob SP, et al. Behavioural symptoms in Alzheimer's disease: phenomenology and treatment. J Clin Psychiatry 1987;48 (suppl 9):9-15. 